\title{
Quality of surgical care of pancreatic cancer in a single payer
}

\section{North American health care system [version 1; peer review: 1}

\section{approved, 1 approved with reservations]}

\author{
Scott Hurton ${ }^{1}$, Robin Urquhart ${ }^{1}$, Cynthia Kendall ${ }^{1}$, Margaret Jorgensen ${ }^{1}$, \\ Geoff Porter ${ }^{1}$, Adrian Levy², Michele Molinari1,2 \\ ${ }^{1}$ Department of Surgery, Dalhousie University, Halifax, Canada \\ 2Department of Community Health and Epidemiology, Dalhousie University, Halifax, Canada
}

V1 First published: 15 Aug 2016, 5:1989
https://doi.org/10.12688/f1000research.9199.1

Latest published: 15 Aug 2016, 5:1989

https://doi.org/10.12688/f1000research.9199.1

\begin{abstract}
Introduction: Quality of surgical care of Canadian patients with pancreatic cancer (PC) is inadequately known. Primary aim of this study was to analyze the quality of care received by patients who underwent resections of PC in Nova Scotia over a 10-year period (2001-2011).
\end{abstract}

Methods: All patients with PC (n. 1094) were identified using provincial cancer registries and only adult patients with resectable disease were included in the study (n. 109). Well established disease-specific quality indicators (QIs) were used as references. The proportion of patients who met those QIs was calculated. The average and $95 \%$ confidence intervals of QIs were compared between patients treated in Nova Scotia and published references.

Results: Surgical therapy was performed in $9.9 \%$ of patients. Perioperative morbidity and mortality occurred in $25 \%$ and $5 \%$ of patients respectively. Overall survival was $57 \%$ at 1 year, $18 \%$ at 3 year and $9 \%$ at 5 year. R1 resections occurred in $38 \%$ of patients. When compared to published quality measures, patients in Nova Scotia had similar outcomes except for an inferior number of lymph nodes found in the surgical specimens ( 9 vs. $19 ; \mathrm{P}<0.05$ ). On the other hand, a significant proportion of patients did not fully meet several QIs linked to preoperative, surgical pathology and postoperative care. Conclusions: In Nova Scotia, the proportion of patients who underwent surgery for PC was lower than expected. Although perioperative morbidity, mortality and survival rates were comparable to published references, many did not meet established standard QIs.

Keywords pancreatic cancer , surgical care , Nova Scotia, quality indicators , mortality , survival

\section{Open Peer Review}

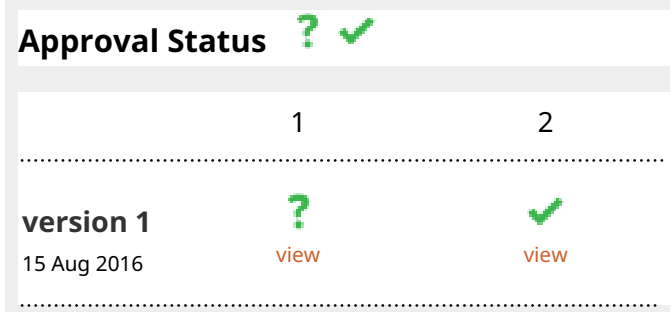

1. Rachel Foskett-Tharby, University of Birmingham, Birmingham, UK

2. Sulaiman Nanji, Queen's University, Kingston, Canada

Any reports and responses or comments on the article can be found at the end of the article. 
Corresponding author: Michele Molinari (michele.molinari@cdha.nshealth.ca)

Competing interests: No competing interests were disclosed.

Grant information: This study was supported by a grant of \$CAN 100,000 provided by Craig's Cause Pancreatic Cancer Society, a registered Canadian Charity Society, Business Number: 842352759RR0001, webpage: http://www.craigscause.ca/.

The funders had no role in study design, data collection and analysis, decision to publish, or preparation of the manuscript.

Copyright: @ 2016 Hurton S et al. This is an open access article distributed under the terms of the Creative Commons Attribution License , which permits unrestricted use, distribution, and reproduction in any medium, provided the original work is properly cited.

How to cite this article: Hurton S, Urquhart R, Kendall C et al. Quality of surgical care of pancreatic cancer in a single payer North American health care system [version 1; peer review: 1 approved, 1 approved with reservations] F1000Research 2016, 5:1989 https://doi.org/10.12688/f1000research.9199.1

First published: 15 Aug 2016, 5:1989 https://doi.org/10.12688/f1000research.9199.1 


\section{Introduction}

Pancreatic cancer (PC) is one of the most common gastrointestinal malignancies in North America and Europe ${ }^{1,2}$. In comparison to many other malignancies, it has poor prognosis due to late diagnosis and low response to current chemo-radiation therapies ${ }^{2}$. In addition to aggressive biology, recent data also suggest that, within different health systems, the quality of care provided to PC patients is heterogeneous and often suboptimal ${ }^{3-11}$. In Canada, national data published in $2014^{12}$ revealed that the overall 5-year survival of patients diagnosed with PC correlated with the geographical areas of their residence, with Nova Scotia having the lowest survival rate $(4.7 \%$ 5-year survival in comparison to the national rate of $9.1 \% ; \mathrm{P}<0.05)^{13}$. Several hypotheses have been raised to explain these findings ${ }^{11}$ : lower socio-economic conditions, higher alcohol and tobacco consumption, more sedentary lifestyle and higher prevalence of obesity than in other Canadian provinces $^{14-16}$. Alternatively, these results might be due to lower quality of care delivered to PC patients living in Nova Scotia where, contrary to several other Canadian provinces, a formal and coordinated quality improvement intervention for PC had never occurred $^{11}$.
The primary aim of this study was to compare the quality of care and outcomes of patients who underwent surgical therapy for PC in Nova Scotia over a 10-year period using disease-specific quality indicators (QIs) published in the scientific literature as references ${ }^{11,17}$.

\section{Methods}

Patient selection

The study population included a cohort of patients older than 18 years of age who had undergone resection for primary exocrine pancreatic cancers (PC) in the province of Nova Scotia, Canada over a 10-year period (April 1, 2001-March 31, 2011). Diagnostic codes of the International Classification of Disease for Oncology, $3^{\text {rd }}$ edition (ICD-O-3) were used to select patients with PC from the Nova Scotia Cancer Registry (NSCR), a prospectively maintained provincial registry of all patients affected by malignant diseases in the province. Diagnostic codes of malignancies of the exocrine pancreas used for this study are summarized in Table 1. Patients were excluded if affected by pancreatic endocrine neoplasms, lymphomas, sarcomas, metastases from other malignancies or direct invasion of tumors originating in surrounding organs (e.g. retroperitoneum, gastrointestinal tract).

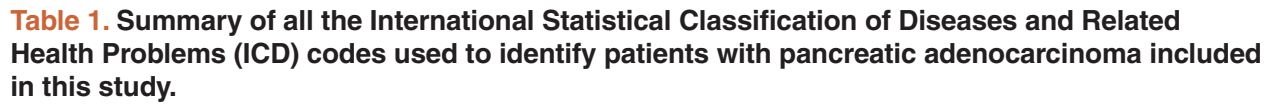

\begin{tabular}{|l|c|c|}
\hline ICD Codes Used for Identification of Location of Pancreatic Tumors & ICD-9-CM & ICD-10-CM \\
\hline Malignant neoplasm of head of pancreas & 157 & C25.0 \\
\hline Malignant neoplasm of the body of pancreas & 157.1 & C25.1 \\
\hline Malignant neoplasm of the tail of pancreas & 157.2 & C25.2 \\
\hline Malignant neoplasm of the pancreatic duct & 157.3 & C25.3 \\
\hline Malignant neoplasm of other specified sites of pancreas & 157.8 & C25.7 \\
\hline Malignant neoplasm of pancreas part unspecified & 157.9 & C25.9 \\
\hline ICD Codes Used for Identification of Tumors Origination from & ICD-0-3 Histology Codes \\
\hline Exocrine Pancreatic Cells: & $8000,8001,8002,8003$, \\
\hline & $8010,8011,8012,8020$, \\
\hline $\begin{array}{l}\text { Neoplasm Malignant; Tumor Cells Malignant Carcinoma NOS; } \\
\text { Undifferentiated Carcinoma; Anaplastic Carcinoma; Pleomorphic }\end{array}$ & $8021,8022,8030,8031$, \\
\hline Carcinoma; Papillary Carcinoma; Papillary Squamous Cell Carcinoma; & $8032,8033,8034,8035$, \\
\hline Adenocarcinoma NOS; Diffuse Adenocarcinoma; Solid Carcinoma & $8050,8052,8140,8141$, \\
\hline NOS; Mucocarcinoid; Adenocarcinoid; Atypical Carcinoid Tumor; & $8142,8143,8144,8145$, \\
\hline Adenocarcinoma with Mixed subtypes; Papillary Adenocarcinoma & $8146,8147,8230,8243$, \\
\hline NOS; Cystoadenocarcinoma NOS; Serous Cystoadenocarcinoma; Solid & $8245,8249,8255,8260$, \\
\hline Pseudopapillary Carcinoma; Intraductal Papillary Mucinous Carcinoma; & $8261,8262,8263,8310$, \\
\hline Mucinous Cystadenocarcinoma NOS; Mucinous Carcinoma/ & $8323,8440,8441,8452$, \\
\hline Adenocarcinoma; Mucin Producing Carcinoma/Adenocarcinoma; & $8453,8470,8472,8473$, \\
\hline Duct Adenocarcinoma; Acinic Cell Adenocarcinoma; Acinar Cell & $8480,8481,8490,8500$, \\
\hline Cystoadenocarcinoma; Adenosquamous Carcinoma; Adenocarcinoma & $8501,8502,8503,8510$, \\
\hline Neuroendocrine Differentaion Pancreatoblastoma; Carcinoma NOS & $8550,8551,8560,8570$, \\
\hline ICD Codes Used for Identification of Tumors Origination from & $8571,8572,8573,8574$, \\
\hline Endocrine Pancreatic Cells & $8575,8576,8971,8980$. \\
\hline Ist Cell & ICD-0-3 Histology Codes \\
\hline
\end{tabular}

Islet Cell Carcinoma Beta-Cell Tumor: Malignant Alpha-Cell Tumor: Malignant Vipoma G-Cell Tumor: Somatostatinoma: Maligant

Enteroglucagonoma: Malignant Bile Duct Adenocarcinoma Bile Duct Cystoadenocarcinoma Carcinoid Tumor Argentafin Carcinoma Tumor Enterochromaffin Cell Tumor Neuroendocrine Carcinoma Insular $8150,8151,8152,8155$ $8153,8156,8157,8160$ $8161,8240,8241,8242$ Carcinoma 
Each patient who satisfied the inclusion criteria was assigned an identification (ID) number to protect patients' privacy. Additional administrative datasets were linked to the NSCR for completion of sociodemographic and clinical data as represented in Figure 1. Linked datasets included the Oncology Patient Information System (OPIS), Medical Service Insurance (MSI) Physician Services, Medical Service Insurance (MSI) Patient Registry, and the Canadian Institutes of Health Information (CIHI) Discharge Abstract Database $(\mathrm{DAD})^{18}$. These datasets were linked to the NSCR by the Population Health Research Unit (PHRU) at Dalhousie University. The methodology used to link these administrative datasets has been described in details in previous manuscripts published by our group ${ }^{17,18}$. Surgical patients were excluded if they underwent palliative interventions such as biliary or gastric bypasses when found to be unresectable intraoperatively.

Approval for this study identified as CDHA-RS/2012-206 was obtained from Capital Health Research Ethics Board Centre for Clinical Research located in room 322B, CCR at 5790 University Avenue, Halifax, NS B3H 1V7, Canada. This ethic review board supervises the good conduct of research projects performed by investigators with appointments at Dalhousie University. In addition, the protocol was also approved by all the ethic review boards $(E R B)$ at each provincial health district where patients received their treatment. Besides Capital Health Research Ethics Board, other ERBs responsible for the approval of this study were: Annapolis
Valley, South Shore and South West Nova Scotia, Cape Breton and Guysborough Antigonish Strait, Colchester-East Hants, Cumberland and Pictou Health Authorities ${ }^{19,20}$.

\section{Selection of quality indicators (QIs)}

The quality of surgical care delivered to patients with PC was measured using QIs proposed by Sabater et al. ${ }^{17}$ and Bilimoria and colleagues ${ }^{11}$. Quality measures selected from Sabater's study ${ }^{21}$ were: perioperative morbidity, perioperative mortality, overall 1, 3 and 5-year survival, number of lymph nodes reported within the surgical specimen and state of resection margins. The international classification of surgical pathologists was used to describe the involvement of resection margins with $\mathrm{R} 0$ margins meaning absence of cancer cells seen microscopically, R1 indicating that cancerous cells could be seen microscopically and R2 when tumor tissue was visible at naked eye on the margins at gross examination. Overall survival was recorded at 1,3 , and 5 years after surgery. All causes of death were considered secondary to recurrent disease and patients who were still alive at the closure of this study were censored. The only variation that occurred in reporting perioperative complications in this study was that adverse events were recorded only if satisfied grade III to $\mathrm{V}$ of Clavien-Dindo classification ${ }^{21}$ contrary to Sabater et $a l .{ }^{17}$ who recommended reporting all grades of perioperative complications. QIs identified from the study by Bilimoria et al. ${ }^{11}$ were summarized in four domains: preoperative, operative, surgical pathology reporting and postoperative outcomes.

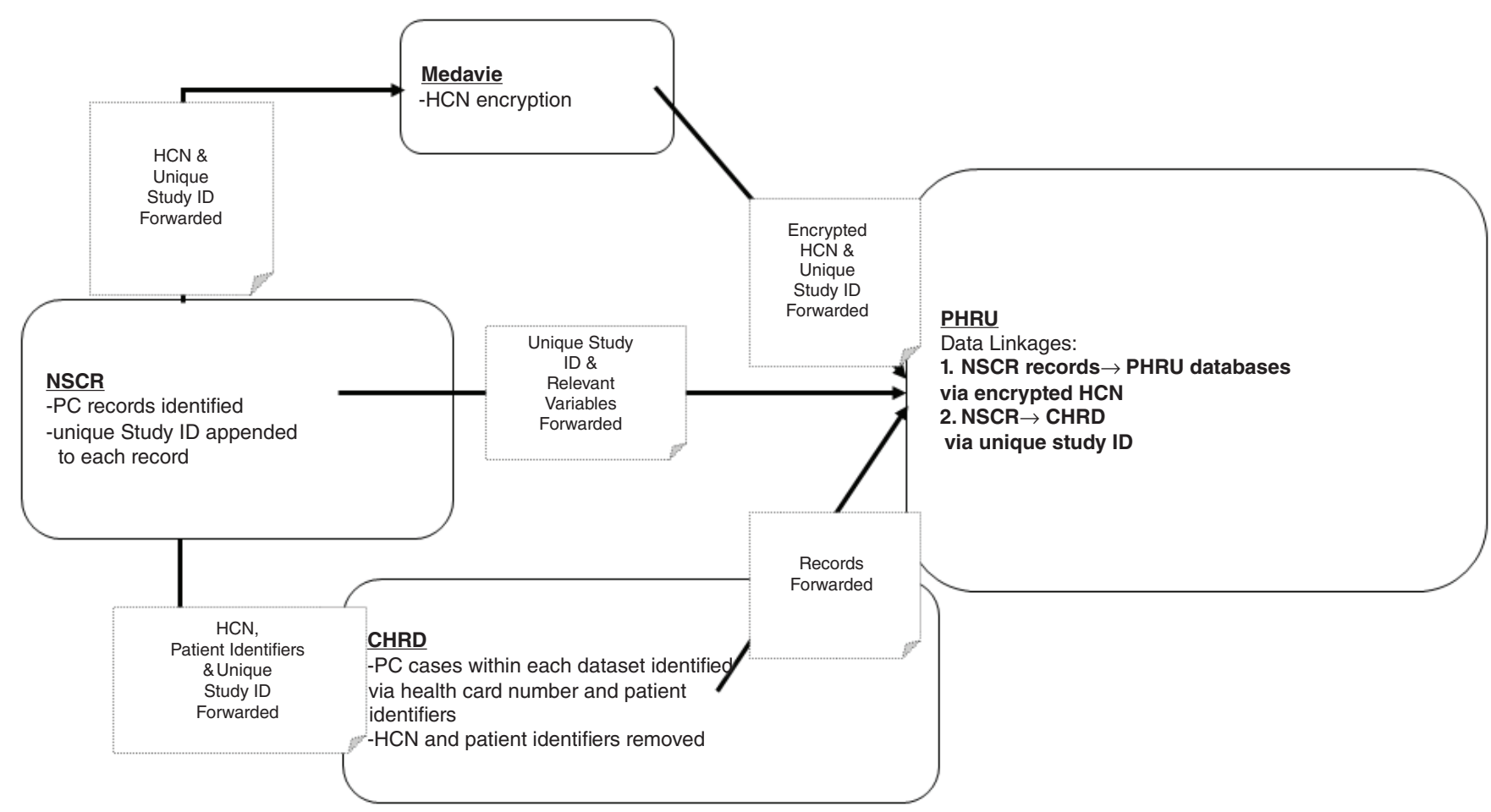

Figure 1. Schematic representation on how all the administrative database linkage was obtained to identify all the individuals affected by pancreatic cancer in Nova Scotia ruing the period between January 1, 2001 and December 31, 2011. Legend: NSCR (Nova Scotia Cancer Registry), HCN (Health Care Number), CHRD (Capital Health Radiology Department), PHRU (Population Health Research Unit, Dalhouse University). 


\section{Statistical analysis}

The quality of care of patients who underwent surgical resection of PC in Nova Scotia was compared to the mean and $95 \%$ confidence interval (CI) of QIs selected by Sabater et al. ${ }^{17}$. In their study, Sabater and colleagues ${ }^{17}$ performed a comprehensive search of practice guidelines, consensus conferences and reviews of pancreatic oncologic surgery and selected clinical relevant indicators of quality with weighted averages and respective 95\% CIs. Comparisons between Nova Scotia and outcome benchmarks were performed using 95\% CI for each of the QIs to test for possible statistically significant differences.

Overall survival analysis was performed using Kaplan-Meier methodology $^{22}$. All statistical analysis was carried out using SAS® (Version 8.2, Cary, North Carolina). Two-tailed analyses were performed unless otherwise specified. Missing data were excluded except when imputation was possible from administrative data. All statistical analyses were considered significant at $\mathrm{p}<0.05$.

\section{Results}

Inclusion criteria were satisfied by 109 patients. Fifteen patients $(13.7 \%)$ were excluded due to significant missing data. As a result, a total of 94 patients were included and represented the study population where the median age was 66.8 years, $41 \%$ were female, and $87 \%$ underwent a pancreaticoduodenectomy (Table 2).

\section{Surgical quality of care}

Perioperative complications occurred in 25 patients $(24.5 \%)$ (95\% CI: $16.2-32.8 \%$ ), and perioperative mortality occurred in 5 (5.9\%) (95\% CI: $2.2-10.5 \%)$. R1 resections occurred in 38 patients (37.3\%) (95\% CI: 37.2-46.6\%) (Figure 2). The mean number of lymph node retrieved in each specimen was 9.0 (95\% CI: 7.7-10.3) and the overall patient survival at 1,3 , and 5 years was $55.1 \%$ (95\% CI: $45.2-63.8 \%$ ), $18.5 \%$ (95\% CI: $11.5-26.7 \%$ ), and $9.4 \%$ (95\% CI: $4.2-17.1 \%$ ), respectively (Figure 2). When data from Nova Scotia were compared to values reported by Sabater et al. ${ }^{17}$, there were no statistically significant differences as $95 \%$ CIs overlapped between the two groups except for the mean number of lymph nodes identified in the pathology specimens and the rate of serious complications that were lower for patients operated in Nova Scotia.

Assessment of other QIs proposed by Bilimoria et al. ${ }^{11}$ revealed that there was significant heterogeneity in the percentage of Nova Scotia patients who met the QIs across all four different domains (Table 3). For example, in the preoperative domain, $82 \%$ of patients had an appropriate cross-sectional imaging study within 2 months from the day of their surgery and $93 \%$ underwent treatment within 2 months after their diagnosis. On the other hand, only $33 \%$ of patients had 10 or more lymph nodes identified in the surgical specimen and only $24 \%$ had a complete TNM stage description in the final surgical pathology report.

\section{Discussion}

In 2014, Statistic Canada ${ }^{12}$ published that in Nova Scotia, 5-year overall survival of PC patients was $4.7 \%$ in comparison to the national rate of $9.1 \%^{23}$. These results confirmed observations from other researchers who reported geographical variations in how
Table 2. Demographic and clinical characteristics of the study population.

\begin{tabular}{|c|c|}
\hline Variable & $\begin{array}{l}\text { Total Number } \\
\text { of Patients } \\
(n=94)\end{array}$ \\
\hline Age in years, median (25th, 75 th) & $\begin{array}{l}66.1(59.3 \\
72.4)\end{array}$ \\
\hline Age > 65 years, $n,(\%)$ & $55(58.5)$ \\
\hline \multicolumn{2}{|l|}{ Gender, n, (\%) } \\
\hline Male & $55(58.5)$ \\
\hline Female & $39(41.4)$ \\
\hline \multicolumn{2}{|l|}{ Elixhauser Comorbidity Index } \\
\hline 0 & $58(61.7)$ \\
\hline 1 & 19 (20.2) \\
\hline$\geq 2$ & $17(18.0)$ \\
\hline \multicolumn{2}{|l|}{ Residence Status, n, (\%) } \\
\hline Urban & $68(72.3)$ \\
\hline Rural & $18(19.1)$ \\
\hline Unknown & $8(8.5)$ \\
\hline \multicolumn{2}{|l|}{ Income Quartile, n, (\%) } \\
\hline Q1 (Low) & $19(20.1)$ \\
\hline Q2 & $13(13.8)$ \\
\hline Q3 & $26(27.6)$ \\
\hline Q4 (High) & $33(35.1)$ \\
\hline \multicolumn{2}{|l|}{ Surgical Therapy, n, (\%) } \\
\hline Pancreaticoduodenenctomy & $82(87.2)$ \\
\hline Distal Pancreatectomy & $12(12.7)$ \\
\hline \multicolumn{2}{|l|}{$\begin{array}{l}\text { Dindo-Clavien Classification of } \\
\text { Perioperative Adverse Events, } \\
\mathrm{n},(\%)\end{array}$} \\
\hline Grade 0-I-II & $70(74.4)$ \\
\hline Grade III & $13(13.8)$ \\
\hline Grade IV & $6(6.3)$ \\
\hline Perioperative Mortality, n, (\%) & $5(5.3)$ \\
\hline \multicolumn{2}{|l|}{ Tumor Location, n, (\%) } \\
\hline Head & $82(87.2)$ \\
\hline Body & $1(1.1)$ \\
\hline Tail & $11(11.7)$ \\
\hline \multicolumn{2}{|l|}{ AJCC T Stage, n, (\%) } \\
\hline 1 & $2(2.1)$ \\
\hline 2 & $13(13.8)$ \\
\hline 3 & $74(78.7)$ \\
\hline 4 & $3(3.2)$ \\
\hline$x$ & $2(2.1)$ \\
\hline \multicolumn{2}{|l|}{ AJCCN N Stage, n, (\%) } \\
\hline 0 & $34(36.2)$ \\
\hline 1 & $58(61.7)$ \\
\hline Unknown & $2(2.1)$ \\
\hline
\end{tabular}




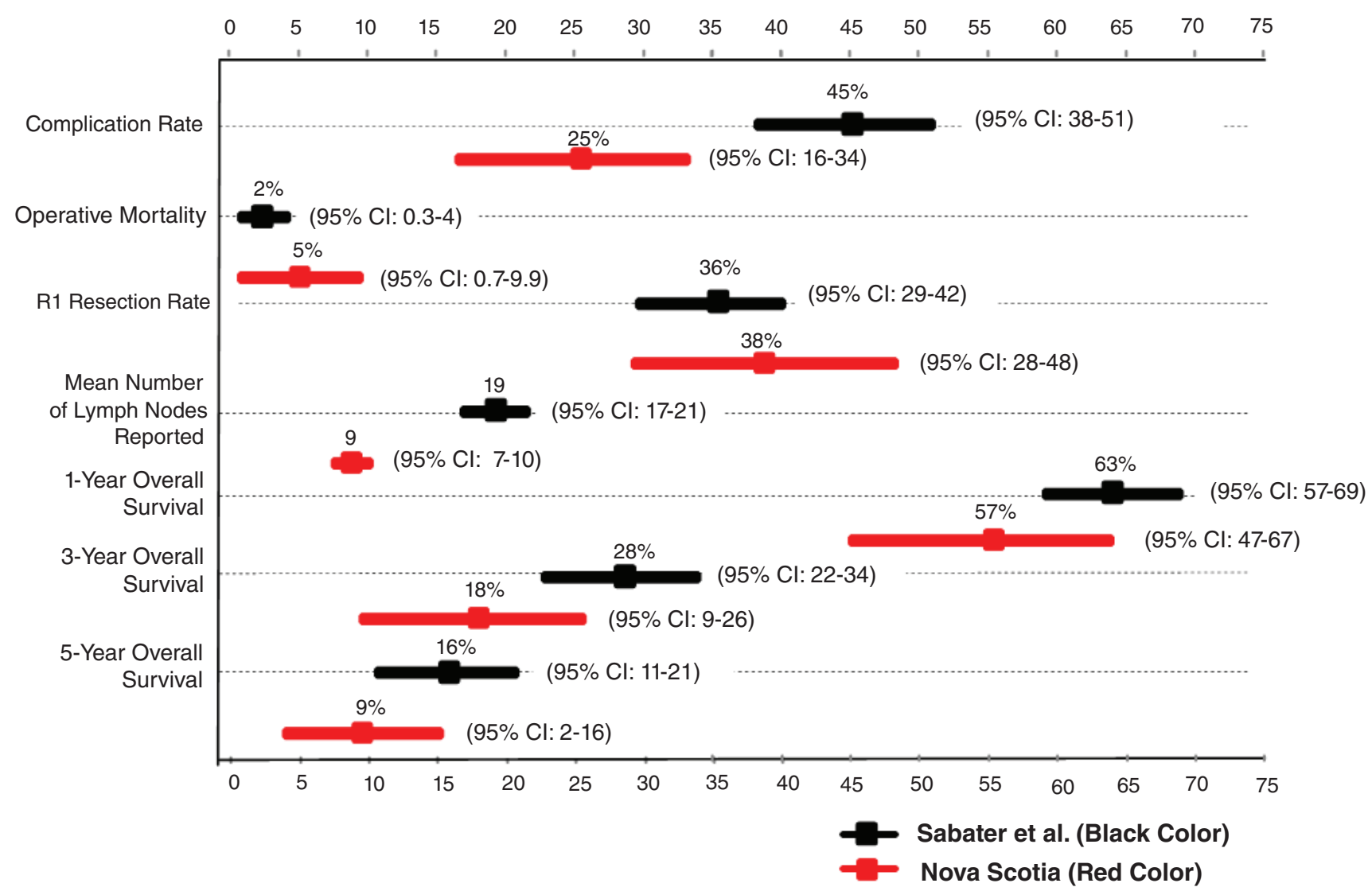

Figure 2. Averages (Square marks) and 95\% confidence intervals (Horizontal lines) of selected quality indicators (QIs) of patients undergoing resections for pancreatic adenocarcinomas (PC). The black squares and horizontal lines represent the references used to compare the outcome of patients who underwent surgical care in Nova Scotia (Red squares and lines). Statistical significant differences are present only if the horizontal lines representing 95\% confidence intervals between the two groups do not overlap.

PC patients are treated and differences in their overall outcomes. Variations treatments depend on multiple factors including physicians' expertise, hospital resources, and patients' characteristics. For example, other researchers have shown that patients who live in rural areas or who belong to lower socio-economic groups have worse outcomes when diagnosed with complex gastrointestinal malignancies or other chronic diseases ${ }^{13,14,24-26}$. This might be due to barriers to access hospitals or specialists, especially in countries where for-profit organizations play an important role in the delivery of healthcare. In Canada, these potential barriers should not exist as health care services are public and, ideally, equally accessible to all citizens.

In a previous paper ${ }^{11}$, our group suggested the possibility that the lower overall survival of PC patients living in Nova Scotia was due to differences in their socio-demographic characteristics when compared to other Canadian provinces ${ }^{14-16}$. Unfortunately, the data provided by Statistic Canada were not sufficiently granular to assess patients' characteristics, and we could not exclude that patients diagnosed with PC in Nova Scotia received suboptimal care. Because of these concerns, we carried out an extensive epidemiological study that included all patients diagnosed with PC over a 10-year period in Nova Scotia with the main intent of assessing the quality of their care using established disease-specific indicators.

One of the main findings of this study was that a small proportion of patients underwent surgical treatment during the study period. In fact, among a total number of 1094 patients diagnosed with PC over a ten-year period, only 109 (9.9\%) underwent radical surgery. This is in contrast to reports from other Canadian centers where radical surgery was feasible in up to $25 \%$ of referrals ${ }^{15}$. Our study, however, has shown that the quality of care of patients who underwent surgery was within the confidence intervals of benchmarks published by Sabater et al. ${ }^{17}$. In other words, there were no significant statistical differences in perioperative mortality, $\mathrm{R} 1$ resection rates and overall survival at 1, 3 and at 5-year after surgery between our population and the parameters used for 


\begin{tabular}{|c|c|c|}
\hline Domain & Quality indicator & $\begin{array}{l}\text { Number and } \\
\text { percentage of } \\
\text { patients who met } \\
\text { established quality } \\
\text { indicators (QIs_ }\end{array}$ \\
\hline & & $\mathbf{N}(\%)$ \\
\hline Preoperative & $\begin{array}{l}\text { Preoperative imaging with CT/MRI within } 2 \text { months } \\
\text { Time from PC diagnosis to first treatment }<2 \text { months }\end{array}$ & $\begin{array}{l}77(81.9) \\
88(93.6)\end{array}$ \\
\hline Operative & $\begin{array}{l}\text { Total lymph nodes examined } \geq 10 \\
\text { Clavien-Dindo grade III-V Complications } \\
\text { R1 Resection rate }\end{array}$ & $\begin{array}{l}31(33.0) \\
24(25.5) \\
36(38.2)\end{array}$ \\
\hline $\begin{array}{l}\text { Surgical } \\
\text { Pathology }\end{array}$ & $\begin{array}{l}\text { Reported tumour grade } \\
\text { Reported tumour histology } \\
\text { Reported tumour size } \\
\text { Reported number of lymph nodes assessed for tumor invasion } \\
\text { Reported pancreatic neck resection margins } \\
\text { Reported pancreatic uncinate process resection margins } \\
\text { Reported pancreatic anterior resection margins } \\
\text { Reported pancreatic posterior resection margins } \\
\text { Reported portal vein resection margins } \\
\text { Reported bile duct resection margins } \\
\text { Reported duodenal resection margins } \\
\text { Reported jejunal resection margins } \\
\text { Reported Lymphovascular Invasion or perineural Invasion } \\
\text { Reported TNM stage }\end{array}$ & $\begin{array}{l}94(100) \\
94(100) \\
90(95.7) \\
93(98.9) \\
90(95.7) \\
46(48.9) \\
4(4.3) \\
16(17.0) \\
10(10.6) \\
76(80.9) \\
78(83.0) \\
77(81.9) \\
70(74.5) \\
23(24.5)\end{array}$ \\
\hline Postoperative & $\begin{array}{l}\text { Consultation with medical Oncology } \\
\text { Documented reason for patients not receiving adjuvant } \\
\text { chemotherapy }\end{array}$ & $\begin{array}{l}50(53.2) \\
43(45.7)\end{array}$ \\
\hline
\end{tabular}

comparison. Nevertheless, there was a trend towards higher perioperative mortality, and overall lower survival rate compared to the pooled data from the scientific literature.

When we analyzed the proportion of patients who met QIs in the four domains proposed by Bilimoria et al. ${ }^{11}$, we found that there were considerable gaps in the quality of surgical pathology reporting and utilization of adjuvant therapies. The quality of pathology reports might have influenced how patients were managed after their operation. In fact, patients with surgical pathology reports that did not mention positive resection margins or lymph node involvement were rarely referred to medical oncologists after their surgeries. The main reason was that in our institution, referral patterns, and medical oncological therapies were not unified and some providers perceived that there was no benefit for postoperative chemotherapy except for patients at high risk of recurrence (e.g. positive resection margins or positive lymph node involvement). Overall, only $53 \%$ of patients in our study were referred to medical oncology service for adjuvant therapy, and only $46 \%$ ended up to be seen by a medical oncologist.

This study has several limitations due to the retrospective nature of its design and the linking of multiple datasets that could have increased the risks of inaccuracy of the data as the primary purpose of these datasets was not for research ${ }^{16}$. Another important limitation is the small number of patients who were included. The overall number of inhabitants in Nova Scotia has been relatively stable with an estimated population of 930,000. Since the yearly incidence of PC in Canada is in the range of 8-11 patients/100,000 inhabitants ${ }^{18}$, we are confident that the majority of patients diagnosed during the study period were identified. However, the resectability rate was much lower than expected as the majority of referrals were unable to undergo surgery due to the advanced stages of the disease or the presence of severe comorbidities that precluded resections. Since surgery remains the only possible curative treatment for PC, the fact that less than $10 \%$ of 
patients were offered this opportunity raises the doubts that a considerable proportion was diagnosed late or not referred for surgical opinion in a timely fashion.

Despite the above limitations, our study is original and, to the best of our knowledge, it is the first to assess the quality of care provided to patients who underwent surgery for $\mathrm{PC}$ at a Canadian provincial level by using established indicators. Also, before this study, there were no reports on the resectability rate of PC in Nova Scotia or the overall 5-year survival of patients who underwent surgery.

In conclusion, patients diagnosed with PC and treated with radical resections in Nova Scotia had acceptable outcomes comparable to published international standards. However, we found that resectability rate was below average and a significant proportion of patients did not meet several QIs including preoperative radiological studies that were older than two months, incomplete surgical pathological reporting and, finally, a low referral rate and utilization of adjuvant therapy. Because survival of patients with PC remains disappointing, it is important to monitor for correctable deficiencies in the health care system. Our study suggests that, in Nova Scotia, there is need to increase early detection and early surgical referral, a more exhaustive pathology reporting and an increased use of adjuvant chemotherapy. A coordinated implementation of all these interventions might improve the overall survival of PC patients in the province. However, areas in which quality improvement strategies are most effective remain unknown and should be explored in future studies.

\section{Data availability}

Nova Scotia's Personal Health Information Act, S.N.S. 2010, c 41 (PHIA), a provincial legislation which governs the collection, use, disclosure, retention and disposal and destruction of personal health information of patients treated in Nova Scotia, came into force on June $12013^{19}$. The goal of this statute is to balance the privacy rights of individuals with respect to their personal health information and the need for researchers and practitioners to collect, use and disclose personal health information as part of providing strong healthcare services in Nova ${ }^{20}$. Due to restrictions imposed by PHIA, the raw data used for this study can only be accessible to investigators who obtain permission from Capital Heatlh Research Ethics Board Centre for Clinical Research and from the Nova Scotia Cancer Registry to use the encrypted database.

Investigators should submit their request to access the encrypted database used for this study to: Capital Health Research Ethics
Board, Room 322, CCR, 5790 University Avenue, Halifax, NS, B3H 1V7, Canada.

\section{Author contributions}

Scott Hurton performed the statistical analysis of the data, performed a systematic review of the literature, wrote the paper and created the figures and tables reported in the manuscript. In addition, he manually searched medical records when data were missing for some of the patients who were included in this study.

Robin Urquhart, Cynthia Kendall, Margaret Jorgensen, Geoff Porter, Adrian Levy: Designed the protocol, assisted in linking all the different administrative provincial datasets used for this study and revised the manuscript.

Michele Molinari: Wrote the study protocol, obtained grant funding to support this study, performed a systematic review of the literature, co-wrote the manuscript.

\section{Competing interests}

No competing interests were disclosed.

\section{Grant information}

This study was supported by a grant of \$CAN 100,000 provided by Craig's Cause Pancreatic Cancer Society, a registered Canadian Charity Society, Business Number: 842352759RR0001, webpage: http://www.craigscause.ca/.

The funders had no role in study design, data collection and analysis, decision to publish, or preparation of the manuscript.

\section{Acknowledgements}

The authors would like to give a special thank to Stefanie CondonOldreive and Paul Oldreive (Founders of Craig's Cause Pancreatic Cancer Society) for their generous support that provided all the necessary funds for this study. In addition, we would like to thank the Canadian Institutes of Health Research (CIHR) for the grant given to Dr. Scott Hurton for his Master Degree studies in Community Health and Evaluation at Dalhousie University.

The authors would like to thank all the volunteers of Craig's Cause Pancreatic Cancer Society for their generosity and fund-raising activities, and Dr. Mark Walsh and Dr. Brock Vair for they operated on many patients who were included in this study.
1. Epidemiology of Pancreatic Cancer in the World. 2014. (Accessed 10 October, 2014). Reference Source

2. Sharma C, Eltawil KM, Renfrew PD, et al:: Advances in diagnosis, treatment and palliation of pancreatic carcinoma: 1990-2010. World J Gastroenterol. 2011; 17(7): 867-97.

PubMed Abstract | Publisher Full Text | Free Full Text

3. Kim C, Owen D, Gill S: Real-world impact of availability of adjuvant therapy on outcomes in patients with resected pancreatic adenocarcinoma: a Canadian Cancer Agency experience. Am J Clin Oncol. 2012; 35(3): 212-5. PubMed Abstract | Publisher Full Text

4. Merkow RP, Bilimoria KY, Bentrem DJ, et al.: National assessment of margin status as a quality indicator after pancreatic cancer surgery. Ann Surg Oncol. 2014; 21(4): 1067-74.

PubMed Abstract | Publisher Full Text

5. Riall TS, Eschbach KA, Townsend CM Jr, et al.: Trends and disparities in 
regionalization of pancreatic resection. J Gastrointest Surg. 2007; 11(10): 1242-51; discussion 51-2.

PubMed Abstract | Publisher Full Text

6. Simons JP, Shah SA, Ng SC, et al:: National complication rates after pancreatectomy: beyond mere mortality. J Gastrointest Surg. 2009; 13(10): 1798-805. PubMed Abstract | Publisher Full Text

7. Simunovic M, To T, Theriault M, et al:: Relation between hospital surgical volume and outcome for pancreatic resection for neoplasm in a publicly funded health care system. CMAJ. 1999; 160(5): 643-8.

PubMed Abstract | Free Full Text

8. Simunovic $\mathrm{M}$, Urbach $\mathrm{D}$, Major $\mathrm{D}$, et al.: Assessing the volume-outcome hypothesis and region-level quality improvement interventions: pancreas cancer surgery in two Canadian Provinces. Ann Surg Oncol. 2010; 17(10): 2537-44.

PubMed Abstract | Publisher Full Text

9. Bilimoria KY, Bentrem DJ, Feinglass JM, et al:: Directing surgical quality improvement initiatives: comparison of perioperative mortality and long-term survival for cancer surgery. J Clin Oncol. 2008; 26(28): 4626-33.

PubMed Abstract | Publisher Full Text

10. Bilimoria KY, Bentrem DJ, Tomlinson JS, et al: Quality of pancreatic cance care at Veterans Administration compared with non-Veterans Administration hospitals. Am J Surg. 2007; 194(5): 588-93.

PubMed Abstract | Publisher Full Text

11. Bilimoria KY, Bentrem DJ, Lillemoe KD, et al:: Assessment of pancreatic cancer care in the United States based on formally developed quality indicators. J Nat Cancer Inst. 2009; 101(12): 848-59.

PubMed Abstract | Publisher Full Text | Free Full Text

12. Canadian Cancer Society's Advisory Committee on Cancer Statistics: Canadian Cancer Statistics 2014. Canadian Cancer Society, 2014; (Accessed May 2, 2014). Reference Source

13. Pancreas Cancer Mortaltity by Geography, Age Group and Gender. Canada.gc.ca, 2014; (Accessed March 26, 2014).

14. Bilimoria KY, Bentrem DJ, Ko CY, et al:: National failure to operate on early stage pancreatic cancer. Ann Surg. 2007; 246(2): 173-80.

PubMed Abstract | Publisher Full Text | Free Full Text

15. Olivié $\mathrm{D}$, Lepanto L, Billiard JS, et al:: Predicting resectability of pancreatic head cancer with multi-detector CT. Surgical and pathologic correlation. JOP. 2007;
8(6): 753-8

PubMed Abstract

16. Ayanian JZ: Using administrative data to assess health care outcomes. Eur Heart J. 1999; 20(23): 1689-91.

PubMed Abstract | Publisher Full Text

17. Sabater L, García-Granero A, Escrig-Sos J, et al:: Outcome quality standards in pancreatic oncologic surgery. Ann Surg Oncol. 2014; 21(4): 1138-46. PubMed Abstract | Publisher Full Text

18. Canadian Institute for Health Information: Discharge Abstract Database (DAD) Metadata. 2015; (Accessed September 9, 2011).

Reference Source

19. Personal Health Information Act (“PHIA"). 2013; (Accessed 07, 2016). Reference Source

20. Cancer Care Nova Scotia. email: info@ccns.nshealth.ca. 2016. Reference Source

21. Dindo D, Demartines N, Clavien PA: Classification of surgical complications: a new proposal with evaluation in a cohort of $\mathbf{6 3 3 6}$ patients and results of a survey. Ann Surg. 2004; 240(2): 205-13.

PubMed Abstract | Publisher Full Text | Free Full Text

22. Kaplan EL, Meier P: Nonparametric estimation from incomplete observations. J Amer Stat Assn. 1958; 53(282): 457-81. Publisher Full Text

23. Hurton S, MacDonald F, Porter G, et al:: The current state of pancreatic cancer in Canada: incidence, mortality, and surgical therapy. Pancreas. 2014; 43(6): 879-85.

PubMed Abstract | Publisher Full Text

24. Enewold L, Harlan LC, Tucker T, et al: Pancreatic cancer in the USA: persistence of undertreatment and poor outcome. J Gastrointest Cancer. 2015; 46(1): 9-20. PubMed Abstract | Publisher Full Text

25. Sun $\mathrm{H}, \mathrm{Ma} \mathrm{H}$, Hong $\mathrm{G}$, et al.: Survival improvement in patients with pancreatic cancer by decade: a period analysis of the SEER database, 1981-2010. Sci Rep. 2014; 4: 6747

PubMed Abstract | Publisher Full Text

26. Murphy MM, Simons JP, Ng SC, et al:: Racial differences in cancer specialist consultation, treatment, and outcomes for locoregional pancreatic adenocarcinoma. Ann Surg Oncol. 2009; 16(11): 2968-77.

PubMed Abstract | Publisher Full Text 


\section{Open Peer Review}

\section{Current Peer Review Status:}

Version 1

Reviewer Report 04 October 2016

https://doi.org/10.5256/f1000research.9901.r16781

(C) 2016 Nanji S. This is an open access peer review report distributed under the terms of the Creative Commons Attribution License, which permits unrestricted use, distribution, and reproduction in any medium, provided the original work is properly cited.

\section{Sulaiman Nanji}

Department of Surgery, Queen's University, Kingston, ON, Canada

This study examines the quality of surgical care in patients undergoing surgical resection for pancreatic adenocarcinoma over a 10-year period (2001-2011) in the Canadian Province on Nova Scotia. The authors use the provincial cancer registry to identify the study cohort based on ICD codes. The quality of surgical care delivered to patients was assessed using previously reported, established disease-specific quality indicators including surgical factors, pathologic measures and short and long-term outcomes. The objective was to determine if patients undergoing curativeintent resection for pancreatic cancer in Nova Scotia were receiving similar quality of care compared to published references.

Our surgical knowledge in the management and outcomes in pancreatic cancer is largely based on retrospective data from large volume centres, often single-institution based series. While these reports provide essential information, it is unclear whether similar outcomes are being realized in routine clinical practice. Health services research using population-based studies, such as this one, provide insight into the management and outcomes achieved in the "real world" and are less limited by referral and selection biases that are inherent in traditional institutional-based series. Moreover, they provide insight into access to care and the adoption of new treatments in routine practice, allowing for identification of gaps and deficiencies in the delivery of appropriate care.

In this study, the authors report inferior outcomes in patients in Nova Scotia compared to published quality measures. Specifically, the resectability rate was below average with only $10 \%$ of patients diagnosed with pancreatic cancer actually undergoing surgical resection with curative intent. They also found a below average rate of referral to medical oncology for consideration of adjuvant therapy, with only half of patients being referred. These are important findings as they identify critical deficiencies in the health care system that are correctable. It is conceivable that with improvements in referral to both surgical and medical oncology in Nova Scotia, long-term outcomes may improve, which at present are substantially worse compared to the reported rates in the literature (5-year overall survival $9 \%$ compared to 16\%). The authors also identified critical gaps in the quality of surgical pathology reporting with poor reporting of margin status, as well as an inferior surgical node retrieval rate with only one-third of patients having $>10$ lymph nodes 
resected. Again, these findings identify important areas of quality improvement.

Given the retrospective, administrative nature of the data, there are inherent limitations such as the lack of detailed information related to post-operative complications and factors that may have influenced referral to surgical and medical oncologists. Moreover, despite using registry data for the entire province of Nova Scotia over 10 years, the actual study cohort is quite small $(n=94)$, limiting more detailed analysis. Perhaps there is a temporal relationship between quality of care and time, with better outcomes in the more recent era? Given the small numbers, it is not possible to explore how quality may have changed over time. Nevertheless, the authors should be commended for the candid reporting of this data, highlighting the insufficiencies in the delivery of care to patients with pancreatic cancer in Nova Scotia. Through their investigation they were able to identify several areas where quality of care can be improved, with a view to achieving better outcomes. This report also underscores the importance of health services research and population-based studies to determine if outcomes in routine practice are indeed comparable to published reports and to identify deficiencies in the health care system in order to better organize, manage and deliver quality care.

Competing Interests: No competing interests were disclosed.

\section{I confirm that I have read this submission and believe that I have an appropriate level of expertise to confirm that it is of an acceptable scientific standard.}

Reviewer Report 05 September 2016

https://doi.org/10.5256/f1000research.9901.r15690

(C) 2016 Foskett-Tharby R. This is an open access peer review report distributed under the terms of the Creative Commons Attribution License, which permits unrestricted use, distribution, and reproduction in any medium, provided the original work is properly cited.

\section{Rachel Foskett-Tharby}

National Collaborating Centre for Indicator Development, Primary Care Clinical Sciences, University of Birmingham, Birmingham, UK

This was an interesting and well written article but the following points of data accuracy and interpretation should be addressed.

1. Table 2 appears to have some missing data. Specifically the numbers of patients reported against each income quartile do not sum to 94 . I'm also not sure if the numbers of patients experiencing a grade 5 perioperative complication have been missed from the table.

2. There is an inconsistency in the numbers of patients with perioperative complications reported in the text on page 5 ( 25 patients) and those reported in Table 2 (19 patients with grade 3 and 4 classifications of complications).

3. The final sentence of paragraph 2 of the results states that there was a statistically significant difference in perioperative morbidity between Nova Scotia and the Sabater et al study. ${ }^{1}$ Surely this has occurred not as a result of differences in practice but due to the 
differences in definition of perioperative morbidity between the studies. This comparison should be recalculated using the same definition (i.e. all grades of the Dindo-Clavien Classification of Perioperative Adverse Events) as the Sabater et al, study and appropriate conclusions drawn.

\section{References}

1. Sabater L, García-Granero A, Escrig-Sos J, Gómez-Mateo Mdel C, et al.: Outcome quality standards in pancreatic oncologic surgery.Ann Surg Oncol. 2014; 21 (4): 1138-46 PubMed Abstract | Publisher Full Text

Competing Interests: No competing interests were disclosed.

\section{I confirm that I have read this submission and believe that I have an appropriate level of expertise to confirm that it is of an acceptable scientific standard, however I have significant reservations, as outlined above.}

\section{Author Response 06 Sep 2016}

Michele Molinari, Dalhousie University, Halifax, Canada

Dear Rachel Foskett-Tharby,

Thank you for your review and for your comments.

Comment 1- Table 2: there has been an error as 3 patients did not have information on their income quartile. The table is missing a row reporting the number of patients with missing value. We will resubmit the table with corrections.

Comment 2- Table 2: there has been an error in reporting complications as the number of patients with grade 0-III Dindo Clavien complications should be $18(19.1 \%)$ and with grade IV Dindo Clavien complications should be 6 (6.3\%).

Comment 3- The differences in perioperative complications between the population operated in Nova Scotia and the values reported by Sabater et al. are due to differences in definitions. In our study, grade I-II were not captured. Therefore, we were not able to include all those complications that did not have any significant clinical impact. Unfortunately, due to the retrospective design of our study, these minor complications were not available for statistical comparison.

Competing Interests: None to report 
The benefits of publishing with F1000Research:

- Your article is published within days, with no editorial bias

- You can publish traditional articles, null/negative results, case reports, data notes and more

- The peer review process is transparent and collaborative

- Your article is indexed in PubMed after passing peer review

- Dedicated customer support at every stage

For pre-submission enquiries, contact research@f1000.com 